\title{
Prevalence of Lower Back Pain in Nurses
}

\author{
Dr. Ms.SukhadaGhodey ${ }^{1}$, Dr. Mrs. Madhura Chincholikar ${ }^{2}$, \\ Dr. Mrs. Snehal Ghodey ${ }^{3}$ \\ ${ }^{1}$ MPTh (Muculoskeletal Sciences) Assistant Professor, MAEER's Physiotherapy College, TalegoanDabhade \\ ${ }^{2}$ MPTh (Musculoskeletal Sciences) \\ ${ }^{3}$ MPTh (Musculoskeletal Sciences) Principal MAEER's Physiotherapy College, TalegaonDabhade
}

\begin{abstract}
Introduction: Nurses offer care and comfort, but they often end up with a pain in the back for their efforts. Nursing is one profession which is susceptible to getting low back pain under their daily activity

Aims: To study the prevalence of low back ache in nurses.

Objectives: To study the prevalence of low back pain in nurses and the distress caused due to it using the DALLAS Pain Questionnaire.
\end{abstract}

Need: To assess the functional disability due low back pain. To give ergonomic advice to the nurses in order to reduce back pain.

Methodology: Female nurses within the age group of 20 to 70 years were taken consent from and were given the DALLAS Pain Questionnaire, on the basis of which the results were inferred

Result was obtained on the basis of graphs and descriptive analysis of the data.

Result: The prevalence of low back pain in nurses included in the study is $98 \%$

It was observed that 70\% of nurses relied on medications, $74 \%$ of the nurses had difficulty in personal care, 90\% in lifting while $86 \%$ in walking, 92\% in sitting, 96\% during standing and $82 \%$ faced problems during sleeping.

Conclusion: Prevalence of low back pain in nurses is 98\% Among the above ADLs, lifting, sitting and standing were found to be the most affected tasks as compared to others. The highest affection of $94 \%$ in activities apart from ADLs was found in travelling and vocation ADLs and work and leisure, the prevalence is more in first 5 years of experience as compared to 6 to 10 yrs of experience. Further on with increase in experience the prevalence shows increasing trends.

\section{Prevalence Of Lower Back Pain In Nurses}

Nursing is a healthcare profession focused on the care of individuals, families, and communities so they may attain, maintain, or recover optimal health and quality of life from conception to death. Nursing includes the promotion of health, prevention of illness, and the care of ill, disabled and dying people. ${ }^{[21]}$

The unique function of the nurse is to assist the sick individual, in the performance of those activities contributing to health or activities that he would perform unaided if he had the necessary strength, will or knowledge. ${ }^{[20]}$

The aim of the nursing community worldwide is for its professionals to ensure quality care for all, while maintaining their credentials, code of ethics, standards, and competencies, and continuing their education. ${ }^{[20]}$

Nurses who work in emergency department and ICU, where all patients are highly dependent; constant attention and fast action from nurses is needed. So the nurses have to ignore their own safety to save the patients of life.

Nurses that work in the ICU are also very prone to back problems. These nurses often deal with patients that have lost consciousness. These patients present a unique challenge as they cannot do anything for themselves. ICU nurses make more frequent rounds to ensure patients receive any needed treatment. They also must do all of the patient movement on their own. The patient is not awake to help with any part of the process, causing them to become extremely hard to move. These patients must also be moved or turned every few hours so that bed sores do not appear. The number of patients turned multiplied by the two hour turn over frequency, creates an atmosphere ripe with the possibility of back pain and problems. ${ }^{[18]}$

Transferring patients and making up patient beds is really hard on a nurse's back. This is compounded by the fact that a nurse repeats these actions multiple times during a day, for days on end. Typically, nurses may find themselves lifting an average of twenty patients daily. This is in addition to moving an average eight patients from their bed to a chair and back. This movement is worsened by the weight of the patient, which typically exceeds 100 pounds. This surpasses what other professions would consider to be allowable, especially at this rate of occurrence.

"Patients are sicker and bigger than they've been historically," explains Schaumleffel, making nurses' jobs more dangerous to their own health. The frequency of manual labor on the job also increases the risk 
throughout a career. "Back injuries are micro traumas — the damage accumulates over time," she says. The more you work in awkward postures or lift heavy loads, the greater your risk. If a patient is unconscious, nurses will try to turn him every two hours or so to prevent bed sores. ${ }^{[19]}$

Pain is an unpleasant emotional state felt in the mind but identifiable as arising in a part of the body. In other words, it is a subjective sensation. Pain is a defense mechanism designed to make the subject protect an injured part from further damage. Low back pain (LBP), perhaps more accurately called lumbago or lumbosacral pain, occurs below the 12th rib and above the gluteal folds.

Low back pain is a well-recognized cause of morbidity in the industrialized world, where several studies have reported the occurrence of LBP in general population and occupational settings . The complaint of back pain is among the most common medical conditions.

Causes

The most common causes of low back pain are:

- Injury or overuse of muscles, ligaments, and joints.

- Pressure on nerve roots in the spinal canal. This can be caused by:

- A herniated disc, sometimes brought on by repeated vibration or motion (as during sport activity or when using a machine or lifting in the wrong way) or by a sudden heavy strain or increased pressure to the lower back.

- Osteoarthritis, usually caused by getting older. When osteoarthritis affects the small joints in the spine, it can lead to back pain. Osteoarthritis in other joints, such as the hips, can cause you to limp or to change the way you walk. This can also lead to back pain.

- Spondylolisthesis, a defect that allows one vertebra to slide over another.

- Spinal stenosis, or narrowing of the spinal canal, which is usually caused by getting older.

- Fractures of the vertebrae caused by a lot of force, such as from an auto or bicycle accident, a direct blow to the spine, or compressing the spine by falling onto the buttocks or head.

- Spinal deformities, including curvature problems such as severe scoliosis or kyphosis.

- Compression fractures. These are more common among post-menopausal women with osteoporosis and in men or women after long-term corticosteroid use. In a person with osteoporosis, even a small amount of force put on the spine, as from a sneeze, may cause a compression fracture.

Depression usually accompanies chronic pain, and this has an adverse effect on the nurses' morale and job performance the impact on the nursing service should be taken seriously when one considers that back pain is the leading cause of disability and absenteeism in the working population

Back pain can be assessed using many numerical scoring questionnaires. These include Dallas Pain Questionnaire $^{[5]}$, Roland- Morris Disability Questionnaire for pain disability ${ }^{[3]}$, McGill Pain Questionnaire ${ }^{[1]}$ ,The Quebec Back Pain Disability Scale ${ }^{[4]}$, Oswestry Back disability[2], Bournemouth Questionnaire for Measuring Outcome in Patients with Low Back Pain[7].

The Dallas pain Questionnaire is 16-item questionnaire assessing functional activity and emotional capacity in chronic spinal pain sufferers. Taken from a cognitive behavioral perspective, scored on visual analogue scales measured from $0-100 \%$, it evaluates 4 aspects of patient's lives 1) daily activities - walking, sitting, standing; 2) work and leisure; 3 ) anxiety and mood; 4) social interest and interpersonal skills

The work and leisure dimension of the DPQ do not appear in the rest of the questionnaires.

The French version of the Dallas Pain Questionnaire is valid, reproducible, and sensitive to change in chronic low back pain patients.

The Dallas Pain Questionnaire (DPQ) was developed to assess the amount of chronic spinal pain that affects four aspects (daily and work-leisure activities, anxiety-depression, and social interest) of the patients' lives. Results of the DPQ's statistical properties suggest that the DPQ is an externally reliable instrument as well as internally consistent. Two factors emerged from factor structure analysis. Factor 1 represents functional activities and Factor 2 represents emotional capacities.

Knowledge of the incidence and trends of pain can help to identify injury and minimize it before more serious incidents occur.In addition to this an ergonomic advice for the wise use of back with biomechanical knowledge can be suggested to the nurses. Hence the need of the study.

\section{Aims And Objectives}

Aims: To study the incidence of low back ache in nurses.

Objectives: To study the prevalence of low back pain in nurses and the distress caused due to it.

- To find the effect of low back pain on various activities like personal care, lifting, walking, sitting, standing, sleeping, social life, travelling, vocation, mood, interpersonal relations and social interaction.

- After the data collection of a sample of 50 nurses was completed, the data collection sheets and the questionnaires were assessed and the scoring was done. 


\section{Material And Methodology}

The study was conducted in Dr. BhausahebSardesai General Hospital, TalegaonDabhade. It was a Questionnaire based type of study done with Simple Random Sampling. The sample size was 50 nurses which included nurses from 20 to 60 yrs of age. The exclusion criteria was Nurses who have history of trauma to the back or the lower limb. The study was conducted using DALLAS Questionnaire for low back pain as the assessment tool.

Procedure of conduction of survey was appropriately explained to the subjects. All details and information were given to the subjects to full satisfaction. Patient was given assurance about information being kept undisclosed.Written consent was taken from subjects for their affirmation for participating in the study.Data collection forms were filled, which included: Name, Age, Experience,Menstrual status, Address and Contact no.After getting the written consent and data, the Dallas questionnaire for low back pain was handed to the subjects. The DPQ is a 16-item instrument to assess the four aspects of daily living affected by chronic back pain: day-to-day activities, such as pain and intensity, personal care, lifting, standing, sitting, walking and sleeping; work and leisure activities, such as social life, travelling and vocational; anxiety-depression status, including anxiety and mood, emotional control and depression; and social interest, such as interpersonal relationship, social support and punishing responses. Each item is scored with a VAS, divided into five, six, seven or eight small segments (it depends on the question). Scale extremities are labelled with specific words (e.g. 'no pain'/'all the time') and with percentage $(0 \% / 100 \%)$. For every specific question, the patient marks the point on the scale which represents his/her condition. After the data collection of a sample of 50 nurses was completed, the data collection sheets and the questionnaires were assessed and the scoring was done.

Scoring of the four general factors is accomplished by assigning values for each item of 0 to the lefthand segment, 1 to the next segment, 2 to the next segment, and so on to the last segment. These individual ratings are summed and multiplied by a constant for a percentage of pain impact for that general area of life events. Items I through VII are summed and multiplied by 3 to obtain the percentage of pain impact on Daily Activities. Items VIII through X, XI through XIII, and XIV through XVI are each summed and multiplied by 5 to determine pain impacts for areas of Work/Leisure, Anxiety/Depression, and Social Activities, respectively. These overall percentages are graphed for a profile summary. Result was obtained on the basis of graphs and analysis of the data. Scores of 0-39 indicate mildly disabling pain, 40-84 moderately disabling pain, and 85 severely disabling pain.

\section{Results}

Graph 1: Demographic dataAge wise distribution of subjects

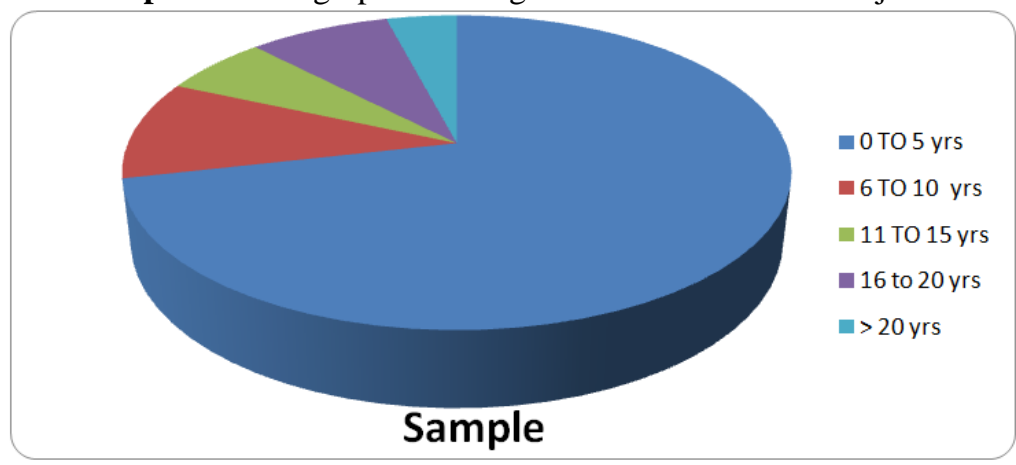

Graph 2: Prevalence of low back pain in nurses

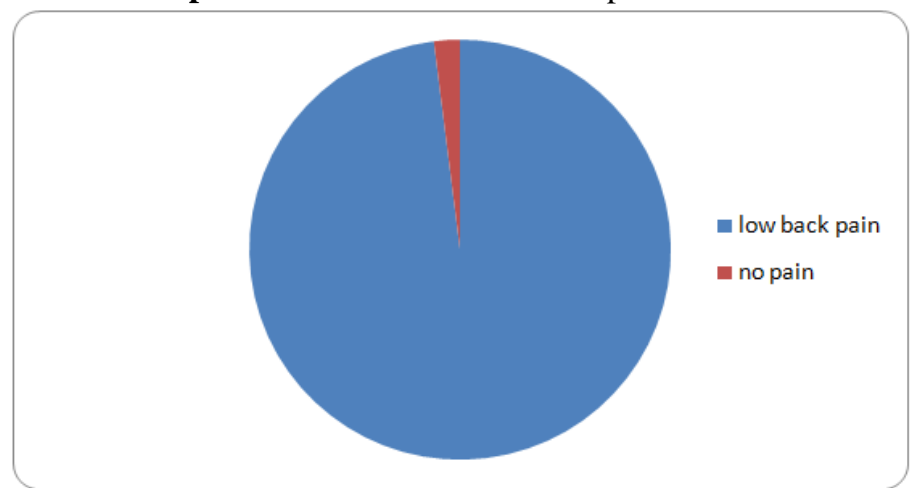

The prevalence of low back pain in nurses included in the study is $\mathbf{9 8 \%}$ 
Graph 3: Prevalence of low back pain in each of the component included in Dallas Pain Questionnaire. Total sample: 50

\begin{tabular}{|l|l|}
\hline TITLE & Percentage \\
\hline RELIANCE ON MEDICATION -I & 70 \\
\hline PERSONAL CARE-II & 74 \\
\hline LIFTING-III & 90 \\
\hline WALKING-IV & 86 \\
\hline SITTING-V & 92 \\
\hline STANDING-VI & 96 \\
\hline SLEEPING-VII & 82 \\
\hline SOCIAL LIFE-VIII & 80 \\
\hline TRAVELLING-IX & 94 \\
\hline VOCATIONAL-X & 94 \\
\hline ANXIETY-XI & 80 \\
\hline EMOTIONAL CONTROL-XII & 88 \\
\hline DEPRESSION-XIII & 78 \\
\hline IP RELATIONS-XIV & 74 \\
\hline SOCIAL SUPPORT-XV & 80 \\
\hline PUNISHING R-XVI & 82 \\
\hline
\end{tabular}

\section{Percentage}

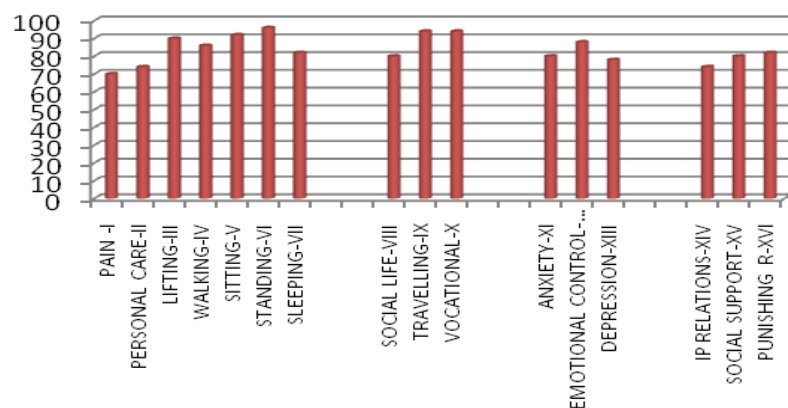

- Percentage

Graph 4:Title: Age wise prevalence of low back pain in each of the component included in Dallas Pain Questionnaire

\begin{tabular}{|c|c|c|c|c|c|c|}
\hline Percentage & GRP & 0 TO 5 & 6 TO 10 & 11 TO 15 & 16 to 20 & $>20$ \\
\hline & $\begin{array}{ll}\text { RELIANCE } & \text { ON } \\
\text { MEDICATION -I } & \end{array}$ & 62 & 60 & 100 & 100 & 100 \\
\hline & PERSONAL CARE-II & 80 & 60 & 66.66 & 75 & 100 \\
\hline & LIFTING-III & 94.28 & 80 & 100 & 100 & 100 \\
\hline & WALKING-IV & 88.57 & 100 & 100 & 75 & 100 \\
\hline & SITTING-V & 97.14 & 80 & 100 & 100 & 100 \\
\hline & STANDING-VI & 97.14 & 100 & 100 & 75 & 100 \\
\hline & SLEEPING-VII & 85.71 & 40 & 100 & 100 & 100 \\
\hline & & & & & & \\
\hline & SOCIAL LIFE-VIII & 85.71 & 60 & & 100 & 100 \\
\hline & TRAVELLING-IX & 94.28 & 100 & 100 & 100 & 100 \\
\hline & VOCATIONAL-X & 97.14 & 100 & 100 & 100 & 100 \\
\hline & ANXIETY-XI & 88.57 & 40 & 100 & 100 & 50 \\
\hline & EMOTIONAL CONTROL-XII & 91.42 & 80 & 100 & 100 & 100 \\
\hline & DEPRESSION-XIII & 80 & 80 & 100 & 100 & 100 \\
\hline & IP RELATIONS-XIV & 77.14 & 40 & 100 & 100 & 100 \\
\hline & SOCIAL SUPPORT-XV & 88.57 & 40 & 100 & 50 & 100 \\
\hline & PUNISHING R-XVI & 88.57 & 60 & 100 & 75 & 100 \\
\hline
\end{tabular}




\section{Discussion}

Pain is an unpleasant sensory and emotional experience associated with actual or potential tissue damage, or described in terms of such damage. (Meyer, 1990) Most tissues of the body possess a system of nerve endings which, being particularly sensitive to tissue dysfunction, may be referred to as nocioceptive system. The free nerve endings of the nocioceptive system provide the means by which we are made aware of the pain. Wyke describes the distribution of the nocioceptive receptor system in the lumbar area: it is found in the skin and subcutaneous tissue; throughout the fibrous capsule of all the synovial apophyseal joints and saroiliac joints; in the ligaments; an the fascia; the flaval and interspinous ligaments and sacro-iliac ligaments; in the periosteum covering the vertebral bodies and arches, and in the the fascia, aponeuroses and tendons attached thereto; and also in the spinal dura matter, including the dural sleeves surrounding the nerve roots. "In no circumstances this receptor system is relatively (although not completely) inactive; but its afferent activity is markedly enhanced when its constituent unmyelinated fibres are depolarized with the application of mechanical forces to the containing tissues that sufficiently stress, deform or damage it (as with pressure, distraction, distention, abrasion, contusion or laceration) or by their exposure to the presence in the surrounding tissue fluid from traumatized, inflamed, necrosing or metabolically abnormal tissues." (18)

Mechanical low back pain (LBP) remains the second most common symptom-related reason for seeing a physician. Mechanical LBP represents the most common cause of disability and is generally associated with a work-related injury. According to Edgar Vieira, a doctoral student in the University of Alberta, Nurses suffer from work-related low back pain more often than workers in other professions. (REF)

The study of prevalence of low back pain in nurses showed that $98 \%$ of nurses have low back pain of varying intensities.

It was observed that $70 \%$ of nurses relied on medications for relieving their low back pain. $74 \%$ of the nurses had difficulty in their personal care, $90 \%$ experienced pain during lifting while $86 \%$ experienced problem in walking, $92 \%$ had difficulty in sitting , 96\% had difficulty during standing and $82 \%$ faced problems during sleeping. Among the above ADLs, lifting, sitting and standing were found to be the most affected tasks as compared to others.

Lifting is an occupational task performed commonly done by nurses. Improper lifting techniques and movements ${ }^{11}$ associated with lifting are known to trigger the onset of LBP. Lifting produces strain which is often a precipitating factor to pain, especially when heavy, prolonged and repeated lifting are involved.

Nachemson $^{19}$ describes the effects of intradiscal pressure when certain positions are adopted while weights are held in the hands. Lifting from the forward bent position is one of the most stressful activities.

The causes of LBP during lifting could be:

1. Increase in intra- abdominal pressure during lifting

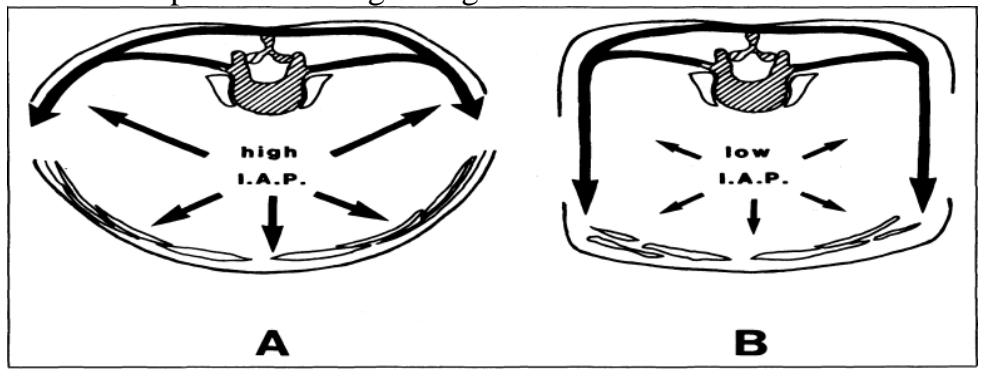

2. Compressive forces acting on the intervertebral discs

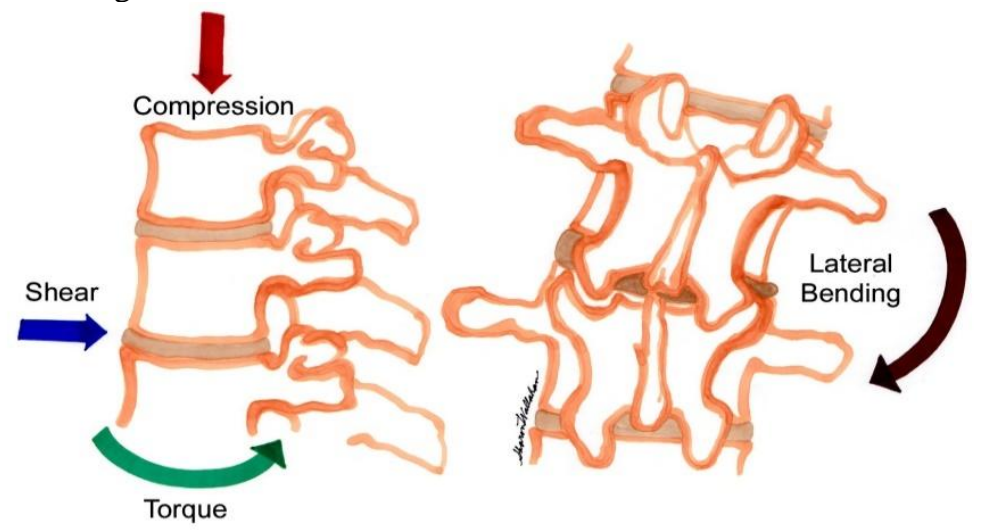

$\because$ 
3. Repeated stress to the posterior ligamentous structures (thoraco lumbar fascia, posterior zygapophyseal joint capsules, ligamentum flavum)

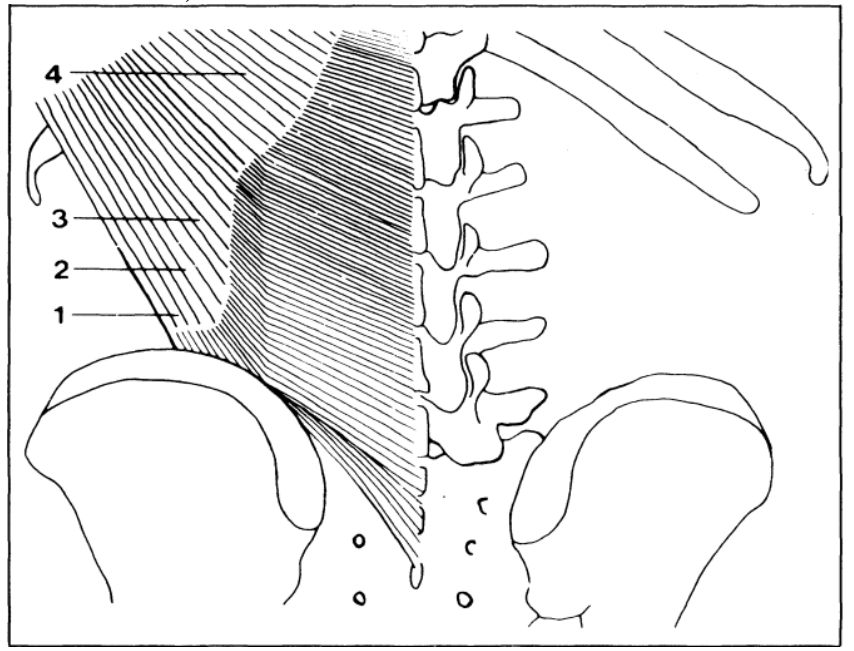

Static work postures were also linked to an increased risk of LBP. Included in these postures were prolonged sitting, standing, and stooping. Sitting for long periods of time (especially in a fixed position) is particularly detrimental to your back health as well as your general health. Prolonged sitting fatigues and strains the lower back. Poor sitting posture makes matters worse.

While sitting, there is a common tendency to allow the pelvis to tilt backward, causing the lower back to lose its natural lordotic curve at lumbar spine. This creates a pull on the muscles and ligaments and uneven compression of the intervertebral discs in the lower back and can lead to lower back pain. Sitting with the pelvis tilted forward creates an excessive lordosis of lower back which also places extra stress on the lower back. Rounding the upper back (slouching) and/or the holding the head forward is also common while sitting and is a common cause of neck and shoulder pain. In relaxed sitting the lumbar spine falls into full flexion. This increases the stress on the posterior annular wall.

While some muscles may suffer from overuse from prolonged sitting, others are not being used at all. The abdominal muscles are often relaxed while sitting, letting the stomach sag out .Even with good sitting posture, sitting in one position for too long can cause back strain.

During periods of PS (prolonged standing), we periodically alter postural position ${ }^{[12]}$. These changes are believed to be triggered by the postural control system to reduce musculoskeletal discomfort and fatigue ${ }^{[13]}$. The underlying causes of such postural modifications could derive from the need to enhance venous pump activity (venouspooling) or decrease pressure over joint tissues. Previous studies have characterized the postural alterations that occur during PS. Deficits observed in CLBP subjects could be related to postural orientation deficits as a consequence of altered proprioceptive input or sensory integration. According to a study performed, after the prolonged standing period, CLBP subjects presented greater postural sway than healthy subjects. Increased postural sway during quiet standing has been also shown in previous studies

Increase in low back pain is a neuromuscular indication of fatigue or discomfort, since standing for prolonged periods has been shown to cause fatigue. Standing, especially relaxed standing, places the lower lumbar spine in full end range extension which means that certain structures are on full stretch. Walking accentuates extension- that is, it further increases the lordosis of the lumbar spine as the hind leg by its backward movement brings the pelvis into forward inclination. The highest affection of $94 \%$ in activities apart from ADLs was found in travelling and vocation (at work). There is evidence of linking vibrations and low back pain. Various aetiological factors associated with vehicular vibrations, like flattening of the lumbar lordosis, increased motion segment flexibility disc pressure and mechanical softening. Due to the vibrational force travelling is disabled in low back pain. At work nurses perform all the above mentioned activities like lifting, prolonged standing, and prolonged standing and hence work is the maximally affected domain.

As seen in graph 4 , on comparison of 4 domains in various age groups, it was found that that in in the first two domains i.e. ADLs and work and leisure, the prevalence is more in first 5 years of experience as compared to 6 to $10 \mathrm{yrs}$ of experience. Further on with increase in experience the prevalence shows increasing trends. This finding could be as the nurses in the first group were unaccustomed to the work activities, there was no conditioning to the muscles which caused more discomfort. In the next group as the conditioning takes place, the discomfort decreases. In the later groups the pain increases as the degenerative processes due to aging starts. Findings in the last two domains i.e. mood and anxiety and social interaction are not relevant. 
When compared on the basis of intensity of pain, the pain during various activities i.e. ADLs and work and leisure show increasing trends with increase in experience. Where as mood and social interaction shows no relevance. Nevertheless, along with functional disabilities low backache also affects social and psychological aspects that influence the pain experience including anxiety, depression, sleeplessness and distress. Studies show that psychological distress is linked with chronic low back pain. People who are depressed, anxious or stressed are at a greater risk for low backache Major depression is thought to be four times greater in people with chronic back pain than in the general population (Sullivan, Reesor, Mikail\& Fisher, 1992) In practice, depression in people with back pain has mostly been defined by scores on questionnaires. ${ }^{31}$ Clyde and Williams, for example, noted that a high proportion of such patients have been identified as depressed on this basis $^{32}$

\section{Conclusion}

- $\quad$ Prevalence of low back pain in nurses is $98 \%$

- Among the above ADLs, lifting, sitting and standing were found to be the most affected tasks as compared to others.

- The highest affection of $94 \%$ in activities apart from ADLs was found in travelling and vocation

- $\mathrm{ADLs}$ and work and leisure, the prevalence is more in first 5 years of experience as compared to 6 to $10 \mathrm{yrs}$ of experience. Further on with increase in experience the prevalence shows increasing trends.

\section{Recommendations for Further Study}

The study can be further done with a larger sample size. A larger area can be taken into consideration.

\section{References}

[1] Melzack R. The McGill Pain Questionnaire: Major properties and scoring methods. Pain. 1975; 1: $277-299$.

[2] Stein C Mendl G. The German counterpart to McGill Pain Questionnaire. Pain. 1988; 32: 251-255.

[3] Oswestry back disability scale Fairbanks et al, 1980.

[4] Roland MO, Morris RW. A study of the natural history of back pain. Part 1: Development of a reliable and sensitive measure of disability in low back pain. Spine 1983; 8: 141-144

[5] Kopec JA, Esdaile JM, Abrahamowicz M, Abenhaim L, Wood-Dauphinee S, Lamping DL, et al. The Quebec Back Pain Disability Scale. Measurement properties. Spine. 1995 Feb 1;20(3):341-52.

[6] Lawis GF, Cuencas R, Selby D, McCoy CE. The development of Dallas pain questionnaire.

[7] Marty M, Blotman F, Avouac B, Rosenberg S, Valat JP. Validation of the French version of Dallas pain questionnaire in chronic low back pain patients. Rev RhumEngl Ed, 1998:65 (5):126-34

[8] Bolton JE Breen AC. The Bournemouth Questionnaire: A short-form comprehensive outcome measure. I. Psychometric properties in back pain patients. J Manipulative and Physiological Therapeutics. 1999; 22: 503-510 (Appendix I page 510)

[9] By Jonathan Cluett, M.D., About.com Guide ; Updated August 16, 2011

[10] Rating scales for low back pain; Umile Giuseppe Longo, MattiaLoppini, Luca Denaro ,Nicola Maffulli§ ; Correspondence to: Nicola Maffulli, Centre for Sports and Exercise Medicine, Barts and The London School of Medicine and Dentistry Mile End Hospital, 275 Bancroft Road, London E1 4DG, UK. E-mail: n.maffulli\{at\}qmul.ac.uk; Accepted November $24,2009$.

[11] To prevent musculoskeletal injuries in the workplace, nurses should adopt safe lifting techniquesBy Anne Federwisch; February 28 , 2005

[12] Magora A: Investigation of the relation between low back pain and occupation. Physical requirements: Sitting, standing, and weight lifting. Industrial Medicine and Surgery 41(12):5-9,1972

[13] Duarte M, Zatsiorsky VM. Patterns of center of pressure migration during prolonged unconstrained standing. Motor Control 1999; 3:12-27.

[14] Duarte M, Zatsiorsky VM. On the fractal properties of natural human standing. Neurosci Lett 2000; 283:173-6.

[15] Alexander KM, LaPier TL. Differences in static balance and weight distribution between normal subjects and subjects with chronic unilateral low back pain. J Orthop Sports Phys Ther 1998;28:378-83.

[16] della Volpe R, Popa T, Ginanneschi F, Spidalieri R, Mazzocchio R, Rossi A. Changes in coordination of postural control during dynamic stance in chronic low back pain patients. Gait Posture 2006;24:349-55.

[17] Mientjes MI, Frank JS. Balance in chronic low back pain patients compared tohealthy people under various conditions in upright standing. ClinBiomech 1999;14:710-6.

[18] Mok NW, Brauer SG, Hodges PW. Hip strategy for balance control in quiet standing is reduced in people with low back pain. Spine 2004;29:E107-112. http://www.medicalnewstoday.com/releases/48381.php (Medical News Today Article Date: 01 Aug 2006 16:00 PDT)

[19] School of Nursing, Faculty of Health and Social Sciences, The Hong Kong Polytechnic University, Hung Hom, Kowloon, Hong Kong, China. hsvyip@inet.polyu.edu.hk

[20] http://en.wikipedia.org/wiki/Nursing

[21] http://www.peopletree.co.in/history.htm

[22] Occupational Health (Pocket Consultant) [Paperback] J. Malcolm Harrington(Author), F. S. Gill(Author), T. C. Aw(Author), Kerry Gardiner(Publisher: Wiley-Blackwell; 4th Edition edition (10 Nov 1998)

[23] http://faculty.ksu.edu.sa/abuadas/PublishingImages/The\%20Prevalence $\% 20$ and $\% 20$ Causes $\% 20$ of $\% 20$ Occupational\%20Back $\% 20 \mathrm{P}$ ain\%20among\%20Nurses\%20in\%20Amman\%20Private\%20Hospitals.pdf

[24] The prevalence and cause of occupational back pain in Hong Kong registered nurses; Peter French RGN PhD ,Lee Fung Wah Flora RN BN(Hons) ; Liu Sum Ping RN BN(Hons) ; LukKar Bo RN BN(Hons) ; Wong Heung Yee Rita RN BN(Hons)Article first published online: 28 JUN 2008DOI: 10.1046/j.1365-2648.1997.1997026380.x

[25] Anthony Delito- Physical Therapy May 1994 vol. 74 pg no. 380- 386

[26] Henrica R SdhiphorstPrueper. In Spine Journal Nov 2007 VOL 7 pg no 525-530. 
[27] Deyo RA, weinstien JN (2001).low back pain. New England Journal of Medicine, page no 344(5):363-370

[28] Elizabeth Quinn, About.com Guide updated November 26,2003 About.com

[29] Article first published online: $29^{\text {th }}$ nov 2005DOI: 10.1002/art.1780301107

[30] Depression and Chronic Back Pain By: William W. Deardorff, PhD

[31] Screening for Symptoms of Depression by Physical Therapists Managing Low Back Pain2004; 84:1157-1166. PHYS THER.

Refshauge Sonia Haggman, Christopher G Maher and Kathryn M

[32] Clyde Z, Williams ACdeC. Depression and mood. In: Linton SJ, ed.New Avenues for the Prevention of Chronic Musculoskeletal Pain and Disabil-ity, Pain Research, and Clinical Management.Vol 12. Amsterdam, the Netherlands: Elsevier Science Publishers $\mathrm{BV} ; 2002: 105-121$. 